\title{
A Contribution of Frankl's Logotherapy to the Interpretation of Near-Death Experiences
}

\author{
James C. Crumbaugh, Ph.D. \\ Frankl Institute of Logotherapy, Southern Region, \\ Biloxi, MS
}

\begin{abstract}
Viktor Frankl's logotherapy seeks to help individuals find meaning in personal life experiences. It resolves potential conflicting sources of meaning by the application of the Laws of Dimensional Ontology, which validate apparently conflicting viewpoints. The application of these laws to the interpretation of near-death experiences (NDEs) resolves the conflict between the orthodox scientific view of NDEs as hallucination and the experiential view of them as experiences of the afterlife to come. Applying Frankl's shadowgraph analogy, both seemingly irreconcilable interpretations of the NDE can be accepted as having valid meaning in different dimensions of reality.
\end{abstract}

When the basic tenets of Viennese psychiatrist Viktor E. Frankl's logotherapy are examined from the perspective of near-death experiences, a relationship between his concepts and the interpretation of the experiences can be seen. The three basic tenets of his orientation may be briefly stated as follows:

First, logotherapy is (a) an existential philosophy, (b) a theory of personality, and (c) a technique for the treatment of neuroses and emotional problems of everyday life.

Second, the fundamental paraphysiological or psychological need of humankind is to find a meaning and purpose in the individual gestalt of one's life experiences. Logotherapy, from the Greek work

James C. Crumbaugh, Ph.D., is a clinical psychologist and Area Director of the Frankl Institute of Logotherapy, The Southern Region. Reprint requests should be addressed to Dr. Crumbaugh at the Frankl Institute of Logotherapy, The Southern Region, 140 Balmoral Avenue, Biloxi, MS 39531. 
logos = meaning, is treatment or guidance in finding meaning in one's personal life experiences, regardless of tragedy even as great as Frankl experienced in four of the concentration camps of Nazi Germany. As an existentialism it holds that humankind is both free and contingent: free to choose the attitude taken toward each of life's experiences, and destined to a fate contingent upon these choices.

Third, finding this meaning is accomplished by review of the individual's life experiences from the standpoint of his or her unique complex of values. A value is an approach to life that has meaning to the individual.

As an example, gaining wealth may be the basic motivational orientation of one individual, who gets greatest meaning from financial success. Another person may be only minimally motivated in this direction. The two have very different goals, but each will find meaning only by pursuit of goals in line with personal values. The predicted outcome of each avenue of pursuit is, of course, open to speculation by proponents of each type of value.

Potentially conflicting sources of meaning may often be mollified by recognition that each source has valid meaning, although in different dimensions. This resolution of conflicts is accomplished by gaining a perception of the different systems of values and finding some common denominator between them. The balance of this paper is devoted to application of the above point to the interpretation of NDEs.

The orthodox scientific interpretation of NDEs versus the experiential interpretation by persons who have had them can be examined for a common denominator. Orthodox science starts with the 17thcentury axiom of John Locke, the first of the British empiricist philosophers. Locke said, "Nihil est in intellectu quo non prius in sensu [Nothing is in the intellect that is not first in the senses]." Thus NDEs have to be experiences gained from the individual's past sensory data. This makes them hallucinations or dreamlike phenomena, which arise under extreme conditions of bodily insult, such as a heart attack, stroke, or car accident. On the other hand, the experiential approach takes them at face value as experiences of an afterlife to come.

The seeming irreconcilability of the two views vanishes or is mollified by what Frankl called the Laws of Dimensional Ontology, or the Laws of Multidimensional Meaning. The First Law states that phenomena that have one meaning in one dimension of reality may have an entirely different meaning in another equally valid dimen- 


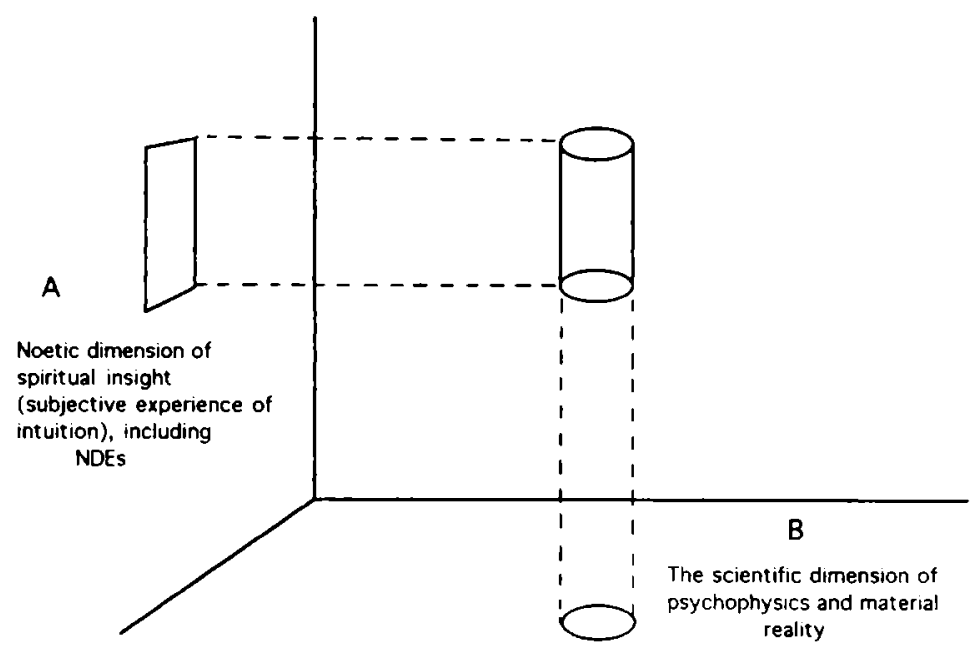

Figure 1. Frankl's First Law of Dimensional Ontology: Phenomena that have one meaning in one dimesion of reality may have an entirely different meaning in anote imension. For example, true NDEs may be seen as such in the spiritual dimension but rejected as false in the physical or material dimension.

sion; this is illustrated in Figure 1. The Second Law states that phenomena that appear identical in one dimension may be easily isolated and differentiated in another dimension; this is illustrated in Figure 2. We will examine each law in turn to see how it applies to the interpretation of NDEs.

\section{The First Law of Dimensional Ontology}

Frankl was a master of analogy, one of the three basic methods of reasoning given to us by Aristotle. While no cause-and-effect relationship can be proven by analogy, it is often the most convincing form of reasoning, because by definition it has "face validity"; that is, it appears reasonable on the face of the issue at hand. An analogy 
$x$

Dimension of Ultimate Reality, never provable by humans but inferred from Dimensions A and B

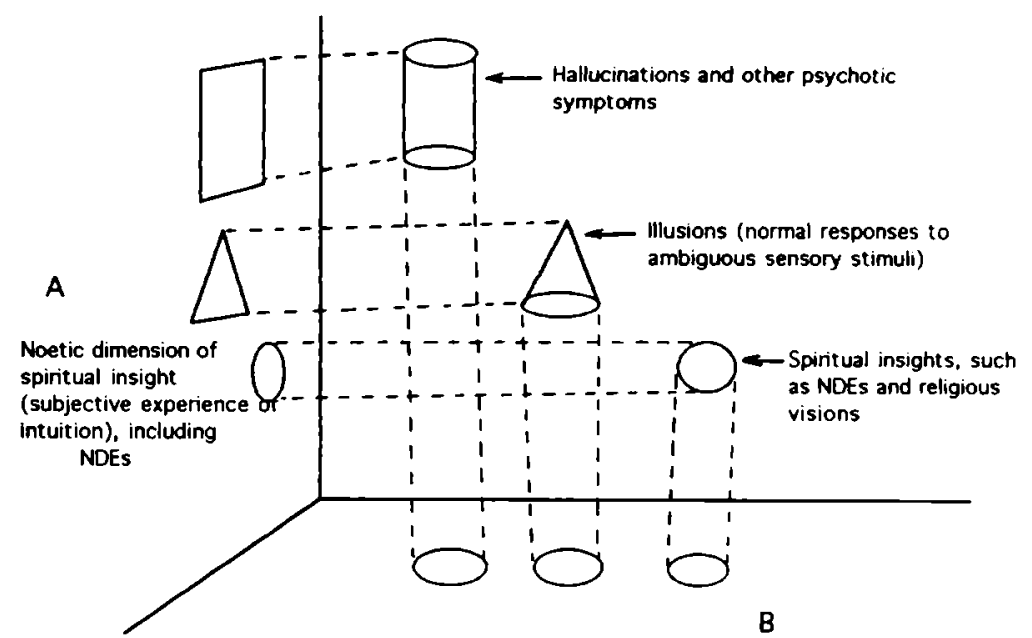

The scientific dimension of psychophysics and material reality

Figure 2. Frankl's Second Law of dimensional Ontology: Phenomena that appear identical in one dimension may be easily distinguished in another dimension. For example, true NDEs may be rejected in the material dimension of physical science but accepted in the spiritual dimension. Materially they seem no different in dimension $B$ from illusions and hallucinations; but they may be discriminated as genuine in the spiritual dimension.

that clearly parallels a situation under consideration may receive more weight than either deductive (syllogistic or a priori) reasoning or inductive (scientific or a posteriori) reasoning, Aristotle's other two methods. And analogy is especially powerful where data from the scientific or experimental method do not exist or are inadequate.

Applying the method of analogy, as Frankl did in his First Law of Dimensional Ontology (or of Multidimensional Meaning), to the meaning of NDEs, we obtain the representation in Figure 1. Frankl illustrated his laws by shadowgraphs cast by an object in two dimensions of space, A and B. Dimension X represents what he called "ultimate meaning" or ultimate reality, which the philosopher Emmanual Kant called das Ding an sich, the thing in itself, and which can never be known with certainty by humankind. It is analogized 
here. A beer can or soft drink can, if illuminated from above, will cast a circular shadow on Dimension B, but if illuminated from the right side it will cast a rectangular shadow on Dimension $A$. Both shadows are equally valid representations of the can, but they differ radically in the two dimensions.

By analogy, the perception of NDEs by scientists and experiencers differs radically in the two dimensions. The NDE may be truly a psychophysical phenomenon of autogenous brain activity based on stored memories of past sensory data on the one hand, and on the other hand, equally truly an insight into another dimension of reality, which Frankl called the noetic dimension, from the Greek word nous $=$ the spiritual or intuitive side of mind. Therefore, proponents of both views of the NDE can find a common meeting ground where they can recognize each other's orientation and still "save face."

Orthodox positivistic scientists will continue to maintain the interpretation of autogenous brain activity generated under stress as the explanation demanded by the scientific "law of parsimony," which says we must take the simplest possible explanation of any causeand-effect relationship. They will continue to reject the experiential view because the actual phenomena reported can be explained without the assumption of an afterlife. On the other hand, experiencers will continue to maintain that the phenomena are extremely real and not just cortical activity, because they seem more real to the experiencer than any amount of abstract logic or scientific analysis of causation.

Neither side has to fall to the other, and both sides maintain a dimension of validity. The common denominator that makes this shadowgraph analogy with NDEs useful is that of validity itself, which can be maintained as equal in both dimensions without either's imposing upon the other.

The reader may ask how it is really possible that NDEs are both intrinsic cortical activity based on past sensory experiences on the one hand, and also true revelations of an afterlife to come. The answer is found in Frankl's First Law and in his admonition to avoid reductionism. He did not deny the material, physical, mechanistic side of human life, but he warned against the fallacious trap of reducing all human experience to that side. Humankind, he held, is composed of three facets: mind, body, and spirit. Mind may be an abstraction for bodily (including brain) function, and spirit is also manifested through bodily activity. But no one has proof that the spirit world does not exist in another dimension than that of human 
experience, or that the dimensions can never overlap in some times and places. True, the burden of proof is scientifically placed on the positive claimants; but since no one presently has proof either way, we are scientifically justified in maintaining a personal faith in whichever camp seems to us as most probably correct.

Perhaps we should note in passing that Frankl has said of NDEs, when Elisabeth Kübler-Ross brought him her data for comment, "While her data do not prove the existence of an afterlife, I don't think we can write them off" (personal comment in my presence, Oakland, California, 1977). And when asked if he believed in an afterlife, he replied that instantly upon death time and space cease to exist for that person, and that all which has been always is: past, present, and future blend, and the queston is impossible to answer. This seems similar to Raymond Moody's conclusions, and it is interesting to note that both Frankl and Moody have doctoral degrees in philosophy as well as medical degrees.

\section{The Second Law of Dimensional Ontology}

But what about differentiation in the noetic dimension between true noetic or spiritual experiences, assuming that such do occur, and phony experiences that are either made up purposely or the simple product of a vivid and creative imagination? Frankl had an answer that can be applied to this also, embodied in his Second Law, depicted in Figure 2. It states that phenomena that appear identical in one dimension may be easily isolated and differentiated in another dimension. Notice in Figure 2 that a true spiritual insight, represented by the circle shadow, can appear the same as illusions or hallucinations in Dimension B, represented by two additional circle shadows. But in the noetic Dimension $A$, these phenomena are easily differentiated, just as the shadowed objects-can, cone, and ball, are differentiated. In other words, those in the noetic or spiritual dimension can perceive the subtle differences and latch onto them, whereas those limited to the material or sensory dimension cannot perceive them.

\section{Conclusion}

In the final analysis, then, how should we view the meaning of NDEs? To be truly scientific we must view them with an open mind, 
recognizing both interpretations as possibly valid and neither as exclusively and necessarily right. To go even further into the noetic or spiritual dimension, we can even cast Frankl's concept into theological terms. Although Frankl himself never entered into theological speculation, he recognized that logotherapy and religion are very compatible. He cautioned, however, that each individual must choose personally whether to step from the platform of logotherapy to the parallel platform of religion. In theological terms, we can assume by faith that God motivates the individual's conscious experiences to enter the noetic dimension and to receive the NDE, while still expressing it through channels of previously perceived sensory data. A suggestion that this is true is found in one of the most universally noted characteristics of NDEs, that the experiencer is at a loss for words to describe the experience: it is ineffable.

The believer can take encouragement from the conclusion that this is exactly what would be expected if the experience had objective reality. If one day it is proven that at least some of these experiences do represent the existence of an afterlife, all people, both living and dead, will be aware of this. But if it is not true, no one will ever know this with certainty. No one will ever be able to taunt a believer with "I told you so," because both will be dead. But the reverse does not protect the unbeliever, because he or she will be conscious in the presence of the believer. Unless an entirely new method of studying these experiences is found, however, neither side will have to worry in this life. In the meantime, encouragement of new research should be the order of the day. 